\title{
Preschool: Producers or Reducers of Inequality Regarding Physical Activity Levels in 4-6 year old Children
}

\author{
Karin Kippe, Pål Lagestad \\ Nord university, Levanger, Norway
}

\begin{abstract}
The study examines preschool children's physical activity level at preschool. Preschool children's activity level at preschool is also investigated related to activity level at leisure, gender, and mothers' education level, income, age and preschools staff's physical activity level. 244 children and 72 preschool staff supplied valid accelerometer data, and mothers' education level, income, and age were measured using a questionnaire. One-way ANOVA, linear regression and multilevel analysis, the linear mixed model (LMM), were utilized as statistical analyses. The results demonstrated that physical activity level during preschool is the main contributor to preschool children's physical activity level on weekdays. Furthermore, boys were more active than girls, and preschool children's physical activity level at both leisure and at preschool were not associated with mothers' age, education level, or income. However, a positive association was found between physical activity level at leisure and at preschool. Physical activity level was significantly different between preschools.
\end{abstract}

\section{Introduction}

Physical activity reduces the risk of illness, improves quality of life, and increases functional ability [1]. Moreover, physical activity strengthens muscles and the skeleton, develops skills, reduces anxiety and depression, bolsters self-confidence, and contributes to social interaction [2]. It is recommended that children engage in physical activity for a minimum of 60 minutes each day with moderate or high intensity (MVPA) [3]. Earlier research has shown, however, that not all children satisfy these health recommendations, and that the physical activity levels that are too low [4-9]. While Berglind et al. [10] found that $32.6 \%$ of the Swedish four-year olds fulfilled the health recommendations of physical activity, Andersen et al. [11] show that almost $60 \%$ of the children [average 3,7 years old], fulfilled these recommendations. Kolle et al. [12] showed that respectively $95.7 \%$ and $87 \%$ of the Norwegian six years old boys and girls fulfilled these recommendations. Several studies have also reported that boys are more active than girls [7, 9, 10, 13-18]. Studies have revealed that, in Norway and other countries, the activity level of children declines with increasing age $[8,12,18-20]$. Another study reported that, from the age of six, time spent being inactive increases on average by 17 minutes for each year up to the age of 15 [1].

Almost all Norwegian children from three- to sixyears-old, are in preschool most of their waking hours [21], and the preschool staff will have a major influence on children's physical activity levels. Consequently, it is asserted that the preschool can contribute to influencing children's health in the short and long term, and also to levelling social differences, which constitutes an important principle underlying public-health work [1]. A study showed that children in Norwegian preschools spent approximately nearly four hours outdoors [22]. According to Herrington and Brussoni [23] outdoor activity, particularly in natural play spaces, boosts children's physical activity. Finn et al. [14] found that more than $50 \%$ of the average daily activity occurred during children's preschool hours. This demonstrates that preschools may be an especially important arena for decreasing social differences due to physical activity level among children. According to both Rossem et al. [24], and Borraccino et al. [25], lifestyle behaviour will follow the same trend from preschool age up to adulthood. Several researchers highlight the importance of preschool staff being involved and making efforts to promote children's physical activity, and furthermore, that policy and practice in preschool greatly impact the total physical activity level of children [7, 26-28].

One of society's major challenges is to maintain the activity level of children and to prevent the development of differences in activity levels based on socio-economic variables [1]. Socio-economic variables appear to exert a major impact on the activity levels of both youths and adults [29, 30]. Cotrell et al. [31] found that children [aged 5 to 15] from families with lower incomes, received more approbation for being physically active outdoors, and their parents more often participated in the activity with them. Kimbro et al. [32] determined that preschool children from families with lower socioeconomic status had more unstructured time, which contributed to more physical activity than it did for children from families with higher socio-economic status. On the other hand, Pate et al. [7] reported little difference in activity level (MVPA) between children aged three to five, considered in relation to parental education. This is supported by

Telford et al. [33], which did not find a link between the physical activity of five- to six-year-olds in their free time, and socio-economic status. The 
previous discussion points to the importance of preschools in relation to preschool children's activity level and reducing inequality in physical activity level among preschool children. However, there is a lack of research that has examined children's activity level in preschool with objective measures, such as accelerometers, and controlling for variables, such as gender, and mothers' education level, income, and age. The main aim of the current study was to elucidate whether the preschools succeeded to reduce inequality in physical activity level among preschool children [4-6 years-old] at leisure, by providing all preschool children with the same activity level at preschool.

The purpose of the study is operationalized into the following four research questions:

1. What is the contribution of preschool children's MVPA at preschool in order to achieve the international health recommendation of 60 MVPA daily?

2. Are there any differences between MVPA at preschool in different preschools and do the preschool staff's and the childrens MVPA correspond?

3. To what extent is preschool children's MVPA at preschool related to gender, their mothers' education level, income and age?

4. Do the preschools succeed to reduce inequality according to the physical activity in MVPA among preschool children that occurs during leisure time?

\section{Material and Methods}

The present study was conducted in collaboration with a larger Ph.D research project (unpublished) that used accelerometers, questionnaires, observations and interviews. However, as the aim of the present study did not comprise all aspects of the data collection, only accelerometer data and questionnaire data were included. To answer the above research questions, accelerometers were used among preschool children and preschool staff, and questionnaires among the children's parents. Accelerometers were chosen because they can detect intensity, frequency, and duration of children's physical activity [12, 34-36]. Moreover, the use of accelerometers make it possible to compare data with a national population study of physical activity level among pre-schoolers [12]. Questionnaires are the most common tool for measuring education level, income, and age.

\subsection{Subjects}

Of 122 preschools in four counsils in NordTroendelag county, 13 preschools were randomly selected to participate in the study, independently of size and type of preschool. The preschools were located in the same socioeconomic area. A condition for participating in the study was that children were full-time in preschool. The 13 preschools included 364 full-time children at the age of 4-6 years. 244 children and 72 preschool staff who worked mainly with the children aged 4-6 had valid accelerometer data. The number of 4-6 year-old children in fulltime preschool varied widely [see Table 1].

\subsection{Procedures}

Accelerometer data and questionnaire data were collected during May and June, 2017. Prior to signing the written consent form and the data collection, preschool teachers and parents received written and oral information about the procedures and ethical standards for testing related to sports science. Actigraph GT1M accelerometers [ActiGraph, Fort Walton Beach, FL, U.S.A.] were utilized to objectively measure preschool teachers and 4-6 year-olds' physical activity over seven consecutive days, which is recommended by several researchers $[12,17,37,38]$. Participants were instructed that the accelerometer had to be placed on the right hip according to Kolle et al. [12], and worn every day except for during sleep, showering, or other activities involving water. During the data collection, the participants [childrens mother and father and preschool staff] received an SMS each morning, reminding them to have their child wear the accelerometer. Raw data output produced from the accelerometers are expressed as counts per minute [CPM], which refers to all acceleration to which the accelerometer has been exposed, divided by the number of minutes the accelerometer has been used [12]. According to the test protocol of Kolle et al. [12], counts are summed during 10 second intervals for the children and 60 second intervals for the preschool staff in order to capture as precise data as possible. Furthermore, the accelerometer data were classified as sedentary, light, moderate and vigorous physical activity, according to the divisions used in a national population study of physical activity level among pre-schoolers [12]. The children's moderate and vigorous physical activity [MVPA] level during the time in preschool is used as the dependent variable in this study. For initializing the accelerometers, to download accelerometer data, and to validate and create accelerometer data [MVPA], Actilife v6.13.3 [ActiGraph, LLC, Pensacola, FL, U.S.A.] was used. Accelerometers were set to start recording at 6:00 am the day after they were distributed and put on, in an effort to counteract the Hawthorne Effect [39]. According to the test protocol, at least 480 minutes of daily recorded activity were required to obtain a valid day, and 20 minutes or more with consecutive zero counts were interpreted as non-wear time and removed [12]. Furthermore, the preschool children were required to have at least two valid days to be included in the 
study. Data between 12:00 am - 5:59 am were excluded due to instructions concerning no accelerometer-wearing during sleep. Finally, the MVPA among preschool children at preschool [school day] was categorized as 8:00 am - 3:29 pm, and MVPA among preschool children at leisure on weekdays was categorized as 6:00 am - 7:59 am, and 3:30 pm - 11:59 pm. Weekend was categorized as 6:00 am - 11:59 am Saturday and Sunday. These operationalisations were made according to feedback from several of the preschool staff and parents of the preschool children, who identified these times as time spent in preschool and leisure, respectively. The questionnaire was designed on the basis of already validated and reliability-tested questions from studies of Hansen et al. [40] and HUNT3 [41]. The questionnaire was pre-tested by 10 parents of 4-6 year-old pre-schoolers in a preschool that was not selected for the study. To visualise the importance of preschool according to preschool children's MVPA level at preschool, MVPA level among preschool children at preschool was categorized from 1 to 13 , with the preschool with the highest MVPA level first [1] and by decreasing activity level until the preschool with the lowest activity level [13]. The distribution of children in the preschools is presented in Table 1.

Table 1. Descriptive data of the 244 children [4-6 years-old] by increasing MVPA at preschool

\begin{tabular}{cc}
\hline Preschool number & Number of children \\
\hline 1 & 10 \\
2 & 5 \\
3 & 34 \\
4 & 25 \\
5 & 14 \\
6 & 6 \\
7 & 27 \\
8 & 29 \\
9 & 16 \\
10 & 28 \\
11 & 16 \\
12 & 24 \\
13 & 10
\end{tabular}

\subsection{Statistics}

The distribution of the dependent variable [MVPA at preschool] seemed to follow a normality curve. However, the Kolmogorov-Smirnov test and the Levene's test [42] showed that the assumption of normality and similar variances was not met $[\mathrm{p}<$ .05]. According to Vincent and Weir [43], however, the $\mathrm{F}$ test [ANOVA] produces valid results even when the sample is not normally distributed or with variability in the sample. This assertion is also supported by Lumley et al. [44], especially related to the high numbers of subjects in the present study. Lumley et al. [44] also make this point regarding the use of linear regression. A one-way ANOVA was employed to determine if there were any differences in preschool children's MVPA at preschool between the preschools, with a post hoc test using Bonferroni corrections. Paired sample t-tests were used to examine differences between children's MVPA level at leisure and preschool. To find to what extent preschool children's MVPA at preschool was related to MVPA at leisure and their mothers' education level, income, and age, linear regression was utilized. However, since the assumptions of continuous variables were not met according to mothers' education level and income (see Table 3), these variables were dichotomized into categorical variables [low education: primary school and high school, high education: university education, and low income: < $500000 \mathrm{nkr}$, and high income: > 500000 $\mathrm{nkr}]$. The level for significance was set at $\mathrm{p}<.05$. Since children are nested in different preschools, data were characterized as hierarchical, as a child's activity level might be affected by other children's activity levels in the same specific preschool. Consequently, a multilevel analysis (linear mixed model (LMM) analysis) was used to examine associations between children's activity levels and preschool staff's activity levels, as it can handle data dependency that occurs in such cases. Moreover, a multilevel analysis has been considered as a suitable method to capture social contexts with several levels [45]. Statistical analysis was performed with SPSS, version 24.0 [IBM, Armonk, NY, U.S.A.].

\section{Results}

The results in Table 2 reveal that $84 \%$ of the children reached the international health recommendations of physical activity of 60 MVPA daily during their weekdays and weekends, taking their total MVPA into account. In addition, only $3.7 \%$ of the children achieved the international health recommendations of physical activity of 60 MVPA daily on weekdays during their leisure, while $39.8 \%$ of the children reached the international health recommendations of physical activity of 60 MVPA daily on weekdays during their time in preschool. Further calculations showed that the time children spent at preschool contributed to $48.8 \%$ of the children's total MVPA.

Table 2. Descriptive characteristics of children [aged 4-6 years-old]: Minutes in MVPA and fulfilling health recommendations 


\begin{tabular}{lccc}
\hline & $\begin{array}{c}\text { Boys } \\
\text { [SD] }\end{array}$ & $\begin{array}{c}\text { Girls } \\
\text { [SD] }\end{array}$ & $\begin{array}{c}\text { Total } \\
\text { [SD] }\end{array}$ \\
\hline Sample size [n] & 125 & 119 & 244 \\
MVPA preschool hours & 61.7 & 55.1 & 58.4 \\
[minutes] & \pm 18.3 & \pm 17.3 & \pm 18.1 \\
MVPA leisure time & 33.6 & 30.8 & 32.3 \\
weekdays [minutes] & \pm 12.6 & \pm 12.8 & \pm 12.8 \\
MVPA weekend & 75.6 & 69.3 & 72.5 \\
[minutes] & \pm 31.5 & \pm 27.9 & \pm 29.9 \\
Health recommendations & & & \\
Met [\%] & 89.6 & 78.2 & 84 \\
Met during preschool & 45.6 & 33.6 & 39.8 \\
hours weekdays [\%] & & & \\
Met outside preschool & 5.6 & 1.7 & 3.7 \\
hours weekdays [\%] & & & \\
Met during weekends [\%] & 0 & 0 & 0 \\
Not met [\%] & 10.4 & 21.8 & 16 \\
\hline
\end{tabular}

A one-way ANOVA revealed that the pre-schoolers' MVPA level at preschool is significantly different between the 13 preschools $[\mathrm{F} 12=5.1, \mathrm{p}<.001]$. In Figure 1, the activity level of children at preschool is organized by increasing [mean] minutes of MVPA in the 13 preschools.

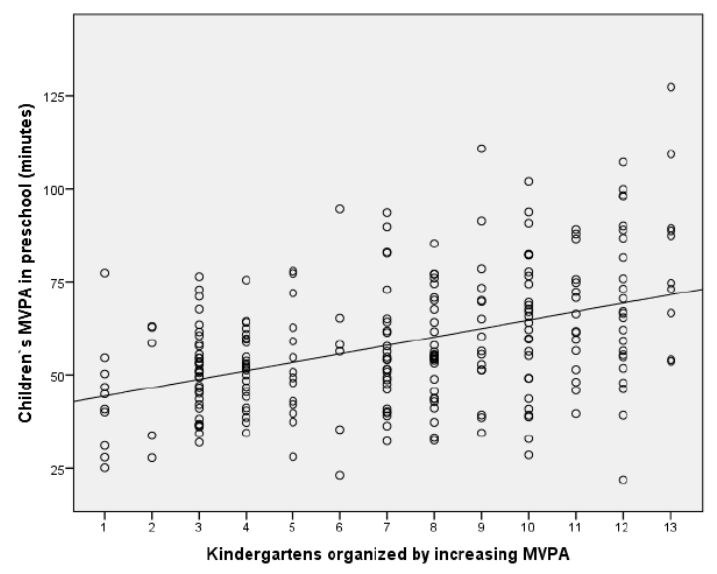

Figure 1. Scatter plot with preschool children's

MVPA at the 13 preschools organized by increasing MVPA level on the X axis, and preschool children's MVPA at preschool on the $\mathrm{Y}$ axis

Post hoc tests with Bonferroni corrections showed that preschools 12 and 13 had significantly higher activity levels than preschools 1-3 and 1-4, respectively $[\mathrm{p}<.05]$. The intraclass correlation revealed that $19.5 \%$ of the total variance in MVPA at preschool is explained by the preschool. To elucidate how the preschool succeeded to reduce differences in activity level that could have arised at leisure time, related to their mothers' education level, income, and age [controlled for the effect of gender], was a main aim of the study. Table 3 present descriptive data concerning how these independent variables are related to preschool children's MVPA, both at preschool and leisure.
Table 3. Characteristics of the children's MVPA level at leisure and preschool on weekdays, according to the independent variables: Mothers' education level, income, and age

\begin{tabular}{lccr}
\hline Mothers' education level & $\begin{array}{c}\text { Leisure time } \\
\text { Mean [SD] }\end{array}$ & $\begin{array}{c}\text { Preschool } \\
\text { Mean [SD] }\end{array}$ \\
\hline Less than 7 years primary school & 21.2 & 71.4 & 2 \\
7-10 years primary school & 33.5 & $48.7^{*}$ & 8 \\
High school, vocational subjects & 33.2 & $55,7^{*}$ & 46 \\
High school, specialization in & 33.5 & $57,3^{*}$ & 22 \\
general studies & & & \\
1-3 years university/college & 28.8 & $53,9^{*}$ & 53 \\
4 years or more at university & 28 & $55,5^{*}$ & 67 \\
Mothers' income & & & \\
Up to 299 000 Nkr & 32.2 & $54,6^{*}$ & 39 \\
300 000 - 499 000 Nkr & 32 & $57,7^{*}$ & 103 \\
500 000 - 699 000 Nkr & 25.8 & $54,4^{*}$ & 38 \\
700 000 - 899 000 Nkr & 19.6 & 48,9 & 3 \\
900 000 - 999 000 Nkr & 24.2 & 63,3 & 4 \\
More than 1000 000 Nkr & 34.2 & 56,4 & 5 \\
Mothers' age & & & \\
20-24 years-old & 34.2 & $57,7^{*}$ & 6 \\
25-29 years-old & 33 & $55,1^{*}$ & 41 \\
30-34 years-old & 31.8 & $59,8^{*}$ & 64 \\
35-39 years-old & 31.4 & $61,7^{*}$ & 49 \\
40 years or older & 26.2 & $57,9^{*}$ & 25 \\
\hline
\end{tabular}

*Significant higher MVPA at preschool time compared to leisure time, $\mathrm{p}<0.05$

$* \mathrm{Nkr}=$ Norwegian kroner

The results in Table 3 show that the children's activity level is significantly higher at preschool time than at leisure time on weekdays in almost all groups. The data indicate that neither mothers' education level, income or age seem to have linear associations with MVPA at preschool or at leisure. The results of the linear regression analyses that are presented in Table 4 identify which of the variables predict activity level at preschool.

Table 4. Factors associated with preschool children's MVPA level at preschool

\begin{tabular}{lc}
\hline Variables & b [st.e], \\
\hline Increasing MVPA preschool & -2.33 \\
& {$[.34], \mathrm{p}<.001$} \\
\hline Mothers' education level [low/high] & -2.61 \\
& {$[2.59], \mathrm{p}=.314$} \\
\hline Mothers' income [low/high] & -.23 \\
\hline Mothers' age & {$[2.92], \mathrm{p}=.937$} \\
\hline MVPA leisure & .14 \\
& $.27], \mathrm{p}=.612$ \\
\hline Children's gender & .59 \\
& {$[1.00], \mathrm{p}<.001$} \\
\hline Constant $/ \mathrm{R}^{2}$ & -5.08 \\
& {$[2.32], \mathrm{p}<.05$} \\
\hline
\end{tabular}

In table 4 the 13 preschool with increasing MVPA was included in the linear regression. The results in 
Table 4 reveal that neither mothers' education level, income, or age predicted MVPA at preschool [p > .05]. However, Table 4 shows that children's MVPA during leisure and children's gender predicted MVPA in preschool.

Figure 2 shows how the preschool children's MVPA at leisure is associated with their MVPA at preschool, and how the preschool succeeded to create high levels of MVPA at preschool for preschool children with low physical activity levels at leisure.

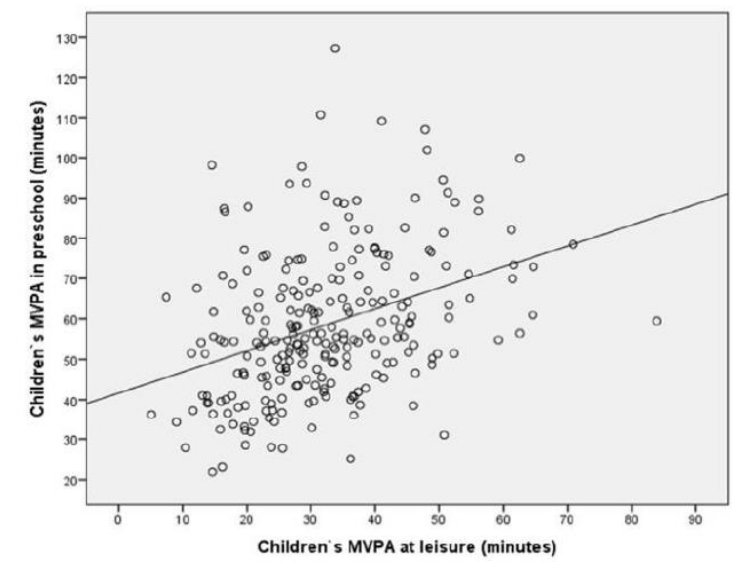

Figure 2. Scatter plot with preschool children's MVPA at leisure on weekdays on the $\mathrm{X}$ axis, and the same preschool children's MVPA at preschool on weekdays on the $\mathrm{Y}$ axis

Figure 3 shows the MVPA level among girls and boys at preschool. It is shown that MVPA level among boys is higher than among girls.

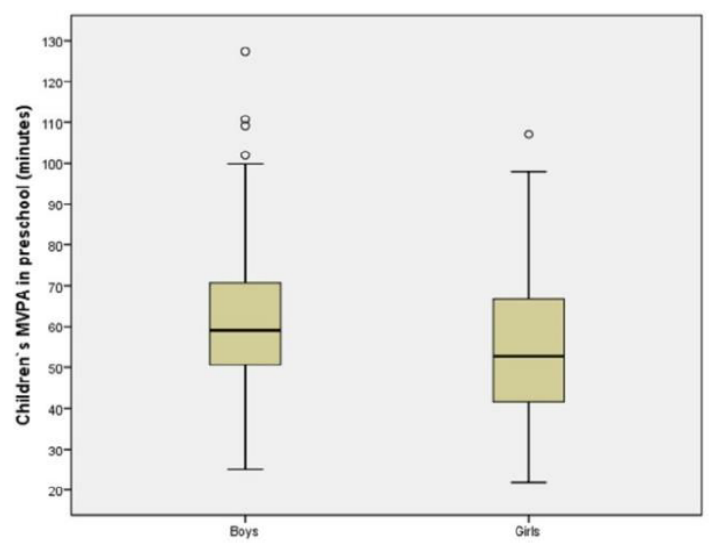

Figure 3. Box plot with boys and girls on the $\mathrm{X}$ axis, and their MVPA at preschool on the $\mathrm{Y}$ axis.

The LMM-analysis shows that a significant association exists between preschool staff's average activity levels during preschool hours and the children's predicted MVPA during preschool hours in each preschool $\left[\mathrm{t}=2,57 ; \mathrm{p}=0,013 ; \mathrm{f}^{2}=0.013\right]$.

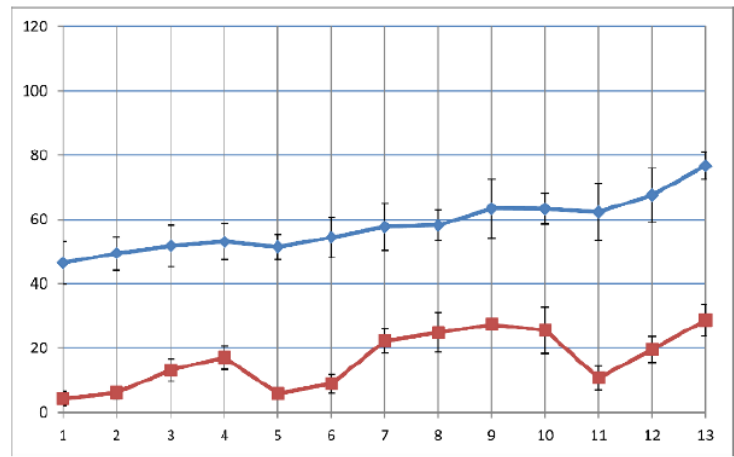

Figure 4. Preschool staff's aggregated data during preschool hours with children's predicted MVPA during preschool hours in each preschool

Figure 4 shows how the average in both the staffs and children's MVPA in each specific preschool correspond.

\section{Discussion}

The first main finding was that $84 \%$ of the children satisfied the international health recommendations for physical activity of 60 minutes of MVPA daily during weekdays and weekends, taking their total MVPA into account. Furthermore, the results showed that MVPA during preschool was the main contributor to preschool children's total MVPA during weekdays, by contributing approximately twice as much to MVPA level during weekdays than MVPA during leisure time, a significant difference [Table 3]. During the entire week, preschool contributed to approximately half of the children's MVPA. This is in accordance with Finn et al. [14], who identified day care as the strongest determinant for physical activity. The activity level of 4-6 years old children in preschool time in our study [mean MVPA $=58.4$ ] is somehow in accordance with other studies. Cauwenberghe et al. [46] found that the average time spent on MVPA was 44.2 min. on days with organized activity, and $34.1 \mathrm{~min}$. without organized activity in preschool. Kain et al. [47] also highligts that organized activity increase childrens physical activity level. Pate et al. [7] reported that children aged three to five were active in MVPA for seven minutes an hour during their time in day care. The second main finding was that MVPA levels were significantly different between the13 preschools. Two of them had significantly higher activity levels during preschool time than the three preschools with the lowest activity levels. This indicate that preschool staff might have a crucial impact on children's activity levels if they provide a supportive environment in which physical activity is prompted regularly. This might contribute to explain the findings in figure 4, as preschool staff from preschools with high activity 
levels might have inspired the children to be more active, or preschool staff chose to be physically active with the children. Vanderloo et al. [2014] highlighted the fact that lack of stimulation or inactive preschool staff as role models will demotivate childrens physical activity. Our findings, that the differences in levels of activity are created in day care, and that no differences exist between children's MVPA out of day care, are supported by both O'Neill et al.[48] and Grøntved et al .[49]. The fact that the differences in children's activity levels are created in preschools led by "professionals", is a surprising finding and problematic from a social perspective. Our findings point to the importance of striving for a culture in which the staff adapt to common values and nurture a collaborative culture for increasing physical activity [50]. Our study may suggest that the three preschools that exhibit the lowest activity levels may need to emphasize work with physical activity to a greater extent than they currently do. Despite the culture of spending lot of time outdoors in Norwegian preschools, which boosts childrens physical activity level [23], some preschools do not manage to give all children sufficient physical activity in preschool. Bjørgen and Svendsen [26] identified the critical importance of preschool staff being involved and making efforts to promote children's physical activity, and highlights the importance of enthusiastic adults that initiate, lead, and are excited about the activities as the key to stimulation of motivation and enjoyment.

The third main finding is that preschool children's MVPA level during preschool time was not associated with mothers' age, education level, or income. However, Table 3 show that childrens' MVPA level at leisure time was not related to their mothers' education level, income, or age. This finding may seem surprising in light of the extant literature. Borraccino et al. [25] found that the physical activity levels of children, increased with parents' socio-economic status and Cleland et al. [51] found that, for boys, the mother was important as a role model for physical activity, and the father's reinforcement [praise for participation in physical activity] and direct support [bringing the child to activities, payment for participation and equipment] constituted the factors that influenced physical activity most positively. For the girls, it was the mother's and siblings active participation in physical activity, that was most critical in relation to physical activity in MVPA. We will argue that our findings indicate that children are naturally active, and that the sociological processes leading to differences in activity level that have been found among adolescents, have not yet been elucidated. The children's sports provisions in Norway do not permit children younger than six to compete in sports [52], and participation in organised sport do not start before children start school. This may contribute to the fact that the focus on the amount and quality of physical activity begins when the children start school. The fact that children's level of physical activity is not associated with socio-economic status, may also be because children have a natural need for movement. It is known that children require a shorter time for restitution regarding heart rate, ventilation, and $\mathrm{CO} 2$ than adolescents, and children's tempo in physical activity may be explained according to restitution time [53].We would point out that our study is based on the socio-economic status of the children's mother. Furthermore, our results revealed that boys were more active than girls, resulting in more boys than girls meeting the health recommendations for physical activity. This is visualized in figure 3 . Thus, our findings support several studies which have found that boys are more active than girls [7, 9, 10, 14-17]. However, it is worth noting that Pate et al. [7] asserted that boys being more active than girls may be linked to how the staff behave as role models for boys and girls in day care, as well as to what the staff think about the gender roles of boys and girls. Pate et al. [7] argues that the differences between girls and boys are due to socio-cultural factors. Typically, in physical activity, boys play in larger groups, with greater risk, and with more bodily contact. Pate et al. [7] also proposed that girls receive less encouragement to participate physically in the course of the day in day care. Penpraze et al. [17] also argued that the differences between girls and boys are not biological, citing that girls are more active during weekends than boys. Our does not find that girls are more active than boys during weekends [Table 2]. The fourth main finding was that a positive association existed between MVPA during leisure time and MVPA at preschool, in which MVPA at preschool increases when MVPA during leisure increases [Table 4]. This is visualized in figure 2. In other words, the preschools do not reduce inequality according to the physical activity level among preschool children that occurs during leisure time. In general, day care increases such differences and contributes to creating even larger differences between low-active and high-active children. O'Neill et al. [48] found that children who did not meet the PA guidelines in school, did not "catch up" with children who met the guidelines. This underlines the importance of increasing the level of physical activity for all children in day care. Preschools are obliged to promote equal opportunities and equality, to base their activities on principles of equal rights and non-discrimination, and to facilitate the children to interact in, and create, an equal society [54]. The staff must reflect on their own attitudes to be able to optimally present and promote equality and equal rights according to physical activity level [54]. Children learn best through support from others, and the preschool staff should provide opportunities to 
enrich the activity by extending children's thinking [55].

The conclusion of the study is that preschools increase the differences in children's total MVPA The study also indicate that children's physical activity level depend on the preschool staff's physical activity level in preschool. This demonstrates the importance of physically active role models to promote increased physical activity level in all children in preschool. This study also demonstrates the importance of striving for a culture in which the staff adapt to common values and nurture a collaborative culture for increasing physical activity.

\section{References}

[1] Ministry of Health and Care Services. Folkehelsemeldingen. God helse - felles ansvar [The public health report. Good health - common responsibility. Report to the Storting no. 34 Oslo [2012]: Ministry of Health and Care Services.

[2] S. Cragg and C. Cameron. Physical activity of Canadian youth - An analysis of 2002 health behaviour in school-aged children data. Canadian Fitness and Lifestyle Research Institute. Ottawa Ontario [2008].

[3] S. Andersen and H.M. Meltzer. Anbefalinger om kosthold, ernæring og fysisk aktivitet [Recommendations for diets, nutrition and physical activity]. Report IS 2170. Oslo [2014]: Norwegian Directorate of Health.

[4] G. Cardon and I.D. Bourdeaudhuij. Comparison of Pedometer and Accelerometer Measures of Physical Activity in Preschool Children. Pediatric Exercise Science [19] [2007], pp 205-214.

[5] K.H. Danielsen, G. Mathisen and J.H. Stålesen. (2019). Målt fysisk aktivitet $\mathrm{i}$ tre barnehager sommer og vinter [Measured Physical Activity in three Preschools Summer and Winter]. Fysioterapeuten nr. 1 [2019], pp 22-27.

[6] K.B. Gunter, K.R. Rice, D.S. Ward and S.G. Trost. Factors associated with physical activity in children attending family childcare homes. Preventive Medicine, 54 [2012], pp 131- 133.

[7] R.R. Pate, K.A. Pfeiffer, S.G. Trost, P. Ziegler and M. Dowda. Physical Activity Among Children Attending Preschools. Pediatrics 114(5) [2004], pp 1258-1263.

[8] J.J. Reilly. Low levels of objectively measured physical activity in preschoolers in childcare. Med Sci Sports Exerc. 42[3] [2010], pp 502-507.

[9] P. Tucker. The physical activity levels of preschoolaged children: A systematic review. Early Childhood Research Quarterly, 23[4] [2008], pp 547-558.

[10] D. Berglind, L. Hansson, P. Tynelius and F. Rasmussen. Levels and Patterns of Objectively Measured Physical Activity and Sedentary Time in 4-Year-Old
Swedish Children. Journal of Physical Activity \& Health 14 [2017], pp 117-122.

[11] E. Andersen, J. Borch-Jenssen, S. Øvreås, H. Ellingsen, K.A. Jørgensen and T. Moser. Objectively measured physical activity level and sedentary behavior in Norwegian children during a week in preschool. Preventive Medicine Reports 7 [2017], pp 130-5.

[12] E. Kolle, J.S. Stokke, B. Hansen, S. Andersen. Fysisk aktivitet blant 6-, 9- og 15 åringer i Norge. Resultater fra en kartlegging i 2011 [Physical activity among 6-, 9- and 11-year olds in Norway. Results of mapping in 2011]. Report 06/2012, IS-2002. Oslo [2012]: Norwegian Directorate of Health.

[13] S. Vale, P. Silva, R. Santos, L. Soares-Miranda and J. Mota.. Compliance with physical activity guidelines in preschool children. Journal of Sports Sciences, 28[6] [2010], pp 603-608.

[14] K. Finn, N. Johannsen and B. Specker. Factors associated with physical activity in preschool children. The Journal of Pediatrics 140 [2002], pp 81-85.

[15] D.M. Jackson, J. J. Reilly, L.A. Kelly, C. Montgomery, S. Grant and J.Y. Paton. Objectively Measured Physical Activity in a Representative Sample of 3- to 4-Year-Old Children. Obesity 11[3] [2003], pp 420425 .

[16] C. Mongomery, J.J. Reilly, D.M. Jackson, L.A. Kelly, C. Slater, J.Y. Paton and S. Grant. Relation between physical activity and energy expenditure in a representative sample of young children. Am J Clin Nutr. 80 [3] [2004], pp 91-96.

[17] V. Penpraze, J.J. Reilly, C.M. MacLean, C. Montgomery, L.A. Kelly, J.Y. Paton, .... and S. Grant. Monitoring of Physical Activity in Young Children: How Much is Enough? Pediatric Exercise Science 18 [2006], pp 483-491.

[18] J.J. Reilly, D.M. Jackson, C. Montgomery, L.A. Kelly, C. Slater, S. Grant and J.Y. Paton. Total energy expenditure and physical activity in young Scottish children: mixed longitudinal study. Lancet 363 [2004], pp 211-212.

[19] A.R. Cooper, A. Goodman, A.S. Page, L.B. Sherar, D.W. Esliger, E.M.F. Van Sluijs,... and U. Ekelund. Objectively measured physical activity and sedentary time in youth: the International children's accelerometry database (ICAD). Int J of Behav Nutr 12 [113] [2015].

[20] T. Hinkley, J. Salmon, A.D. Okely, K. Hesketh and D. Crawford. Correlates of Preschool Children's Physical Activity. American Journal of Preventive Medicine 43[2] [2012], pp 159-167.

[21] Directorate for Education. Tall og analyse av barnehager 2018 [Number and analysis of preschools 2018]. Oslo [2019]: Utdanningsdirektoratet [Directorate for Education]. 
[22] K. Bjørgen. Bevegelsesglede i barnehagen. En kvalitativ studie av 3-5 åringers trivsel, involvering og fysisk aktivitet i barnehagens ulike utemiljø [Joy of movement in day care. A qualitative study of the wellbeing, involvement and physical activity in the varied daycare centre outdoor environment of three- to five-yearolds]. Ph.D. treatise, 2017:26. Trondheim [2017]: Norwegian University of Science and Technology.

[23] S. Herrington and M. Brussoni. Beyond physical Activity: The Importance of Play and Nature-Based Play Spaces for Children's Health and Development. Current Obesity Reports, 4[4] [2015], pp 477-483.

[24] L.V. Rossem, I. Vogel, H.A. Moll, V. Jaddoe, A. Hofman, J.P. Mackenbach and H. Raat. An observational study on socio-economic and ethnic differences in indicators of sedentary behavior and physical activity in preschool children. Preventive Medicine 54 [2012], pp 5560.

[25] A. Borraccino, P. Lemma, R. Lannotti, A. Zambon, G. Lazzeri, M. Giacchi and F. Cavallo F. Socio-economic effects on meeting PA guidelines: comparisons among 32 countries. Med. Sports. Exerc. 41[4] [2009], pp 749-756.

[26] K. Bjørgen and B. Svendsen. Kindergarten practitioners` experience of promoting children's involvement in and enjoyment of physically active play: Does the contagion of physical energy affect physically active play? Contemporary issues in early childhood 16[3] [2015], pp 257-271.

[27] B.E. Mikkelsen. Associations between pedagogues attitudes, praxis and policy in relation to physical activity of children in preschool-results from a cross sectional study of health behaviour amongst Danish pre-school children. International Journal of Pediatric Obesity, 6(S2) [2011], pp 12-15.

[28] L.M. Vanderloo, P. Tucker, A.M. Johnson, M.M. van Zandvoort, S.M. Burke, J.D. Irwin. The influence of centre-based childcare on preschoolers' physical activity levels: a cross-sectional study. International journal of environmental research and public health, 11[2] [2014], pp 1794-1802.

[29] G. Breivik and K. Rafoss. Fysisk aktivitet; omfang, tilrettelegging og sosial ulikhet [Physical activity, scope, facilitation and social inequality]. Oslo [2012]: Norwegian Directorate of Health. Publication no.: IS-0613 ISBN 97882-8081-493-7.

[30] L. Jaeschke, A. Steinbrecher, A. Luzak, A. Puggina, K. Aleksovska, C. Buck,... T. Pischon. Socio-cultural determinants of physical activity across the life course: a 'Determinants of Diet and Physical Activity' (DEDIPAC) umbrella systematic literature review. Int J Behav Nutr Phys Act 14[1] [2017], pp 173.

[31] L. Cotrell, J. Zatezalo, A. Bonasso, J. Lattin, S. Shawley, E. Murphy, ... and W.A. Neal. The relationship between children's physical activity and family income in rural settings: A cross-sectional study. Preventive Medicine Report 2 [2015], pp 99-104.
[32] R.T. Kimbro, J. Brooks-Gunn and S. McLanahan. Young children in urban areas: Links among neighborhood characteristics, weight status, outdoor play, and television watching. Social Science \& Medicine 72 [2011], pp 668676.

[33] A. Telford, J. Salmon, A. Timperio and D. Crawford. Examining Physical Activity Among 5- to 6- and 10- to 12-Year-Old Children: The Children's Leisure Activities Study. Ped Exe Sci 17 [2005], pp 266-280.

[34] K.R. Evenson, D.J. Catellier, K. Gill, K.S. Ondrak and R.G. McMurray. Calibration of two objective measures of physical activity for children. Journal of Sports Science 26 [2008], pp 1557-1565.

[35] G. Nielsen and S. Eiberg S. Barrierer for børns bevægelsesaktivitet [Barriers against children's movement activities]. Danmark [2006]: Sundhedsstyrelsen.

[36] G. Plasqui and K.R. Westerterp. Physical activity assessment with accelerometers: an evaluation against doubly labeled water. Obesity 15[10] [2007], pp 23712379 .

[37] C.L. Addy, J.L. Trilk, M. Dowda, W. Byun and R.R. Pate. Assessing preschool children's physical activity: How many days of accelerometry measurement. Pediatric exercise science 26[1] [2014], pp 103-109.

[38] S.G. Trost, K.L. McIver and R.R. Pate. Conducting accelerometer-based activity assessments in field-based research. Medicine \& Science in Sports \& Exercise, 37[11] [2005], pp 531- 543.

[39] J. McCambridge, J. Witton and D.R. Elbourne. Systematic review of the Hawthorne effect: New concepts are needed to study research participation effects. Journal of Clinical epidemiology 67[3] [2014], pp 267-277.

[40] B.H.Hansen, S.A. Anderssen, J. Steene-Johannesen, U, Ekelund, A.K: Nilsen, I.D. Andersen, K.E. Dalene and E. Kolle. Fysisk aktivitet og sedat tid blant voksne og eldre i Norge. Nasjonal kartlegging 2014-2015 [Physical activity and sedentary time among adults and elderly people in Norway. National mapping 2014-2015]. Report IS-2367. Oslo [2015]: Norwegian Directorate of Health.

[41]HUNT forskningssenter. HUNT 3 Helseundersøkelsen i Nord-Trøndelag [HUNT 3. The health survey in NordTrøndelag]. NTNU research centre, Faculty of Medicine and Health Sciences [2008], Department of Public Health and Nursing.

[42] P. O'Donoghue. Statistics for sport and exercise studies. An introduction. London [2012]: Routledge.

[43] W. Vincent and J.P. Weir. Statistics in Kinesiology4th Edition 4th (fourth) Edition. USA [2012]: Sheridan Books.

[44] T. Lumley, P. Diehr, S. Emerson and L. Chen. The importance of the normality assumption in large public health data sets. Annual Rev. Public Health 23 [2002], pp 151169 . 
[45] T.A. Snijders. Multilevel analysis. International Encyclopedia of Statistical Science. Berlin: Springer [2011], pp 879-882.

[46] E.V. Cauwenberghe, M.D. Craemer, E.D. Decker, I.D. Bourdeaudhuij and G. Cardon. The impact of a teacher-led structured physical activity session in preschoolers' sedentary and physical activity levels. J of Sci and Med in Sport 16[5] [2013], pp 422-426.

[47] J. Kain, B. Leyton, F. Concha, M. Close, J. SotoSánschez and G. Salazar. Preschool children's physical activity intensity during school time: Influence of school schedule. Prev met rep, 8 [2017], pp 6-9.

[48] J.R. O’Neill, K.A. Pfeiffer, M. Dowda and R.R. Pate. In-school and Out-of-school Physical Activity in Preschool Children. Journal of Physical Activity and Health 13 [2016], pp 606-610.

[49] A. Grøntved, G.S. Pedersen, L.B. Andersen, P.L. Kristensen, N.C. Møller and K. Froberg. Personal Characteristics and Demographic Factors Associated with Objectively Measured Physical Activity in Children Attending Preschool. Pediatric Exercise Science 21 [2009], pp 209-219.

[50] L. Wittek. Identitet som lærer [Identity as teacher]. Oslo [2018]: Cappelen Damm AS.

[51] V. Cleland, A. Timperio, J. Salmon, C. Hume, A. Telford and D. Crawford. A Longitudinal Study of the Family Physical Activity Environment and Physical Activity Among Youth. American Journal of Health Promotion 25[3] [2011], pp 159-167.

[52] Norwegian Olympic and Paralympic Committee and Confederation of Sports. Idrettens barnerettigheter. Bestemmelser om barneidrett [Children's rights in sports. Provisions relating to child sports]. Oslo [2015]: Norwegian Olympic and Paralympic Committee and Confederation of sports.

[53] R. C. Bailey, J. Olson, S.L. Pepper, J. Porszasz, T.J. Barstow and D.M. Cooper. The level and tempo of children's physical activities: an observational study. Med and Sci in Sports and Exer 27 [1995], pp 1033-1041.

[54] The General Plan for Norwegian preschools. Oslo [2017]: Utdanningsdirektoratet (Directorate of Education).

[55] Karlsen, L., Lekhal, R. Practioner involvement and support in children's learning during free play in two Norwegian kindergartens. Journal of Early Childhood Research 17[3] [2019], pp 233-246. 